\title{
Cocreative customer practices: Effects of health care customer value cocreation practices on well-being
}

\author{
Janet R. McColl-Kennedy, Suellen J. Hogan, Lars Witell and Hannah Snyder \\ Journal Article
}

\section{Tweet}

N.B.: When citing this work, cite the original article.

Original Publication:

Janet R. McColl-Kennedy, Suellen J. Hogan, Lars Witell and Hannah Snyder, Cocreative customer practices: Effects of health care customer value cocreation practices on well-being, Journal of Business Research, 2017. 70(), pp.55-66.

http://dx.doi.org/10.1016/j.jbusres.2016.07.006

Copyright: Elsevier

http://www.elsevier.com/

Postprint available at: Linköping University Electronic Press

http://urn.kb.se/resolve?urn=urn:nbn:se:liu:diva-133096

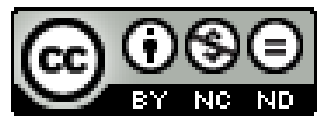

1.0U UNNGDNGS 


\title{
COCREATIVE CUSTOMER PRACTICES: EFFECTS OF HEALTH CARE CUSTOMER VALUE COCREATION PRACTICES ON WELL-BEING
}

\begin{abstract}
Drawing on three studies using data from six separate samples of 1151 health care customers, the authors investigate cocreative customer practices, modeling the effects of customer value cocreation practices on well-being. Results highlight that while positive interactions with medical staff (doctors) lead to increased well-being through engaging in coproducing treatment options, interactions with friends and family and their associated cocreated activities have an even greater positive effect on well-being. Furthermore, several other customer-directed activities have positive indirect effects. Interestingly, activities requiring change can have a negative effect on well-being, except in psychological illnesses, where the opposite is true. The authors conclude with theoretical and managerial implications, highlighting that if interactions and activities with medical professionals are supplemented with customer-directed activities, the positive effect on well-being is significantly enhanced.
\end{abstract}

Key words: service marketing; health; well-being; customer practices; value cocreation practices 


\section{Introduction}

There is growing realization that, rather than being passive recipients of goods and services, customers are active (Gallan et al., 2013) engaging in a range of interactions and activities to cocreate value. These customer value cocreative practices can take several forms. Some activities may involve interactions with service providers, or with friends and family, or even with other customers (McColl-Kennedy et al., 2012). We know that some activities involve more effort than others (Sweeney et al., 2015). However, much less is known about the process of customer value cocreation and the effects of customer value cocreation practices on well-being (Anderson et al., 2013; Ostrom et al., 2015). This is where our paper contributes.

Customer value cocreation and well-being are especially important in health care. There is growing recognition that managing health care, especially in ongoing illness, depends largely on the active involvement of customers (Michie et al., 2003). This broadened role of the health care customer is increasingly being accepted by medical professionals (Wagner et al., 2005). Further, technological advances (Rust \& Huang, 2014) enable better self-diagnosis, prognosis and opens up potentially more treatment options for health care customers.

Given the aging population, ongoing illnesses will undoubtedly increase, putting even more pressure on the health system (Stremersch, 2008). Expenditure on health care in the U.S. alone reached \$2.9 trillion in 2013 (World Health Organization). Over the period 2015-21, health spending is projected to grow at an average rate of 6.2 per cent annually (Centers for Medicare and Medicaid Services). Of the total expenditure, $86 \%$ is on chronic and ongoing illnesses (Agency for Healthcare Research and Quality, 2014). However, collaborating with individuals to manage their health, can reduce the burden on the health system and provides an excellent context for our investigation. 
The purpose of our paper is two-fold, to: (1) investigate customer value cocreation practices across several ongoing illness contexts, identifying the specific interactions and activities that have greatest impact on well-being and; (2) model the effects of customer value cocreation practices on well-being. Drawing on Practice Theory, Construal Level Theory and Self-Regulation Theory, we offer novel insights into customer cocreative practices building on and extending pioneering work in health care value cocreation (Gallan et al., 2013; McCollKennedy et al., 2012; Sweeney et al., 2015). While McColl-Kennedy et al. (2012) provide preliminary evidence of a link between customer cocreative practices and quality of life, and Sweeney et al. (2015) demonstrate a hierarchy of effort in customer activities, ours is the first study to unpack which interactions with whom (medical professionals, other customers, or friends and family) and associated activities, have the greatest impact on well-being across a range of ongoing illnesses. Our main findings are robust across all three studies, but we also demonstrate nuances in how interactions and activities influence well-being across different illnesses.

\section{Conceptual Development}

Three theories, namely Practice Theory, Construal Level Theory and Self-regulation Theory, are presented to help us understand customer cocreative practices followed by a discussion on wellbeing.

\subsection{Practice Theory}

Customer cocreative practices are receiving increasing attention (Xie et al., 2008).

Practices may be defined as "routinized ways in which bodies are moved, objects are handled, subjects are treated, things are described and the world is understood” (Reckwitz, 2002, p. 250). In other words, practices are activities linked by interactions (Schatzki, 2005). The central tenet 
of Practice Theory (PT) is that the way an individual sees the world affects the way that the individual interacts through accepting or adjusting norms of behavior as seen in "interactions" with others. These practices in turn affect the way an individual does things, that is, their “activities” (Kjellberg \& Helgesson, 2006).

While some activities are optional, such as providing a firm with feedback on the service received, or assisting with new service development and promotion through social media, customer participation in certain types of activities (e.g., compliance with basics, such as instructions and procedures), is necessary for a service to be produced and delivered (Podsakoff et al., 2000). For a weight reduction program to work the customer needs to comply with the service provider's directives, such as compliance with instructions and adhering to the weight loss program (Guo et al., 2013). Other customer activities that extend beyond compliance with basic instructions include customer participation in medical consultations (Singh et al., 2004; Gallan et al., 2013), expressing opinions, exploring treatment options (Cegala et al., 2007), and broader still to include for example, changing ways of doing things, distracting activities to take one's mind off the illness, diet and exercise, and actively providing suggestions for the treatment programs (coproducing) (McColl-Kennedy et al., 2012).

While customer participation in interactions and activities with service providers to varying extents is acknowledged, links between customer practices (interactions and activities) and well-being in health care has been relegated largely to narrowly defined compliance behaviors with the service provider's instructions and medical procedures. In accordance with the above discussion, we take the view that value is realized when the beneficiary (customer) integrates resources from various sources, beyond the focal firm or a professional in a given organization (Payne et al., 2008; Xie et al., 2008). Taking this broad Practice Theory-based 
approach, and consistent with McColl-Kennedy et al.'s (2012) definition of customer value cocreation, we view "activities" as performing or doing, while "interactions" are the ways individuals engage with others in their service network.

\subsection{Construal Level Theory}

Construal Level Theory (CLT) (Trope \& Liberman, 2010) helps to further explain interactions and activities between individuals. A central premise of CLT is that psychological distance is linked to mental construal, such that more distant (close) objects or events are construed at the high (low) level, meaning that they are more abstract (concrete). Applied to doing things today, these activities will be viewed as low level construal, while those activities planned in the future will have high levels of construal and greater psychological distance. Psychological distances such as spatial or temporal are automatically associated (Stephan et al., 2010). Accordingly, friends and family are viewed as closest in psychological distance, while others with whom we have no relationship are viewed as being further apart. In our context, relationships with doctors would therefore be viewed as being closer than other health care customers, but not as close as friends and family. Thus, it is expected that interactions are more likely (being psychologically closer in distance) with friends and family, followed by medical professionals, and then with other health care customers.

\subsection{Self-Regulation Theory}

Self-Regulation Theory (Bandura, 1991) implies an individual's ability to control and regulate their behaviors, a necessary skill to achieve personal well-being. Self-regulation is influenced by several individual and contextual aspects such as motivation for the activity and willpower to resist temptations that provide short-term rewards to enable long term rewards. Bandura (1991) argues that individuals can identify which factors influence their sense of well- 
being by systematically varying activities in their daily lives and noting changes. In general, it is suggested that activities with delayed rewards require more effort and self-regulation (Mischel et al., 1989).

While it might reasonably be expected that customer-directed interactions and activities are relevant in chronic illnesses contexts, such as cancer as demonstrated by McColl-Kennedy et al. (2012), it is unknown which sets of customer-directed interactions and activities are most effective in enhancing well-being in ongoing illnesses. Individuals with an ongoing illness face particular challenges in that generally there is no cure and health care customers have to live with the illness long term. Indeed, several important questions remain unanswered. First, are medical staff (doctors)-directed interactions and activities likely to be associated with higher well-being in ongoing illnesses? Second, do certain customer-directed interactions and activities have a greater impact on well-being, and if so, which? Third, do the effects of medical staff (doctors) and customer-directed interactions and activities vary across different types of ongoing illnesses? This is where our study contributes.

\subsection{Well-being}

A highly sought after outcome of interest to both researchers and practitioners is the health care customer's perceptions of their well-being (Berry \& Bendapudi, 2007; Ostrom et al., 2015; Rosenbaum \& Smallwood, 2013). Linking customer value cocreation practices to wellbeing, extends theory by assessing the relative effects of medical staff (doctors)-directed interactions and activities and customer-directed interactions and activities on well-being.

Well-being can be viewed broadly as including an individual's emotions and their global perception of life satisfaction (Diener et al., 1999), and be defined as “a state of flourishing that involves health, happiness and prosperity” (Mick et al., 2012, p. 6). Well-being may also be 
viewed as quality of life (Diener et al., 2003; Ostrom et al., 2015), and is an important outcome in health research assisting in determining the effectiveness of interventions and treatments, as well as understanding health care customers’ service experiences. Several instruments have been developed for measuring well-being. Among the most commonly adopted are the Karnofsky Performance Scale for measuring levels of activity for customers undergoing cancer treatment, the Palliative Performance Scale, the Spitzer Quality of Life Index, and the well-established McGill MQOL index (Cohen et al., 1996).

Consistent with Anderson and Ostrom (2015), we take a broad view of well-being that encompasses social, existential, psychological as well as physical well-being. Accordingly, we adopt the well-established MQOL index that covers multiple domains of well-being from the health care customer's experience (Cohen et al., 1996). This index comprises social well-being which focuses on individuals’ perceptions of their support from others; existential well-being captures the individuals' ability to find meaning and purpose in life and to overcome difficult life events; psychological well-being measures emotions, for example, depression and anxiety; and physical well-being encapsulates the individuals’ perceptions of their physical condition.

\section{Method: Overview of Studies}

In order to achieve our research objectives, we undertook three studies and a pre study. The studies are summarized in Table 1. In Study 1, we use health care customer diaries to identify and categorize customer interactions and activities and develop our conceptual model and hypotheses. Our pre study develops, tests, and validates our measurement model (see Web Appendix). Following established convention, assessment of reliability and construct validity was undertaken for interactions, activities, and well-being scales and their structure using exploratory and confirmatory factor analyses. In Study 2, we test our conceptual model and 
hypotheses using Partial Least Squares (PLS). Finally in Study 3, we further test the stability of our model across three different ongoing illnesses- cardiovascular, musculoskeletal and psychological. The purpose, methods, results and implications of each study are provided next, commencing with Study 1.

- Insert Table 1 about here -

\section{Study 1}

\subsection{Method}

The purpose of Study 1 is to identify and categorize customer practices in ongoing illnesses. Accordingly, twenty health care customers with ongoing illnesses participated in a 14 day diary study (Elg et al., 2012), recording their everyday interactions and activities related to their health problems (e.g., examination, rehabilitation, treatment, advice). We employed content analysis to classify the interactions and activities based on McColl-Kennedy et al. (2012). Following standard procedures (Perreault \& Leigh, 1989), two researchers independently undertook selected coding, paragraph by paragraph, to identify customer practices, obtaining an inter-rater reliability index of .71, above the .70 level recommended for exploratory research (Rust \& Cooil, 1994). Differences in coding were discussed until resolution. A total of 139 activities were identified covering coproduction, complying with basics, co-learning, collating, diet and exercise, change (changing ways of doing things) and distract. The most frequent activity was change, that is, changing behavior $(n=50)$ followed by co-learn $(n=24)$ diet and exercise ( $n=23)$, complying with basics ( $n=17)$, coproduction $(n=12)$, collate $(n=10)$ and distract $(n=9)$. During the content analysis we observed that the activities were cocreated through interactions with medical staff at the medical center $(n=17)$, with other health care customers $(n=3)$ and with friends and family $(n=21)$. Examples of interactions with doctors included 
discussions about treatments "I discussed with my doctor" (in relation to coproducing). Many examples were given of interactions with friends and family, often around time spent with them to distract from the symptoms of their illness. For instance, Ann, 43 years, observes that her mood gets better by spending time with her family. Respondents also provided examples of interactions with other customers. For example, Emma noted "Last Friday I went to the doctor and was prescribed cortisone... The doctor happened to forget to write a prescription, anyone can make a mistake like that, so I'm not angry. However, I was more irritated on Saturday when I called in to the emergency and explained my problem...The nurse that I talked to said that she would notify the doctor and that I would get the prescription before $1 \mathrm{pm}$, before the drug store closes. Do you think that happened? No! Luckily I could borrow medicine from others [other patients] I know with the same condition to get through the weekend."

\subsection{Results}

The identified activities fall within one of three main categories: (1) forming part of a health treatment program; (2) obtaining health related information; and (3) participating in complementary health related activities (Table 2).

- Insert Table 2 about here -

\subsubsection{Health treatment program}

Two types of activities were identified as relating to health treatment programs complying with basics and co-producing. Comply with basics is defined as complying with doctor's orders “doing what the doctors say I should do”, "taking medication as prescribed”, “just being compliant with anything I have to do" (McColl-Kennedy et al., 2012). Both doing as the doctor said and taking prescribed medication was commonly described. For example, Anna described the daily challenge of taking her medications as prescribed, especially the injections 
which she has been instructed by her doctor to self- administer, even though they make her fatigued by complying with the prescribed treatment. She notes "I know I just have to take it".

Coproduce is defined as health care customers assisting with redesigning the treatment programs and reconfiguring the composition of the health care customer's medical team (McColl-Kennedy et al., 2012). For example, Elizabeth actively collaborates in developing a treatment plan providing her doctor with information and providing direct input into what would be most beneficial for her "When we get the results we are going to discuss and put together a plan [for treatment]".

\subsubsection{Health related information}

Two types of activities were identified as health related information - colearn and collate. Colearn is defined as health care customers actively seeking and sharing information with others. Customers displayed this activity by mentioning co-learning activities in interactions with the medical staff and also with family members and other health care customers. Some customers attended a "pain management class", sharing strategies to handle their everyday life with other customers as well as professionals. Another common colearning activity described was "asking questions” and “discussing treatment during doctor’s visits”. For example, Karin described how she discusses physical and psychological aspects of her care by asking questions as well as sharing information about herself and providing feedback to the doctor.

Collate concerns activities such as doing research, obtaining and collating information about their medical condition. Examples pertain mostly to customers reading about their conditions on the Internet, or through other written forms and from their own observations. For example, Melvin searched the Internet investigating if his outbreaks of ulcerative colitis were associated with him quitting smoking. 


\subsubsection{Complementary health related activities}

Three types of activities were identified as complementary health related activities - diet and exercise, change and distract. Diet and exercise involves health care customer activities such as monitoring and maintaining a healthy diet, actively trying to eat foods that are good for health and keeping fit. Several respondents reflected on their diet, trying to figure out what food to eat and what food to exclude, and changing their intake accordingly. For example, Max describes how he monitors his diet by avoiding coffee and fat to keep swelling in his stomach to a minimum. Many examples were provided where customers exercised to feel better, as well as where customers experimented with meditation and massage to help with relaxation.

Change is defined as customer activities such as organizing day to day activities to fit around their health situation, and changing things in their life to help their situation. Activities included physical (not being able to walk the dog), psychological (changing the way you think), social (changing the way you interact with others) and practical (organizing your day differently). For Agnes change meant having "to accept help from others” in relation to taking care of her children.

Distract is defined as customer activities in keeping busy, distracting themselves so as not to think about their medical situation and/or focusing on their interests. Johanna described enjoying time spent with her children as it distracted her from thinking about her condition. Roger, “always feels better” when his children come to visit because it distracts his thoughts away from his health problems. McColl-Kennedy et al. (2012) identified this activity but grouped it under “changing ways of doing things”. We see this activity as a distinct activity and label it "distract”.

\subsection{Study 1 Implications}


Study 1 revealed three broad categories of customer value cocreation practices that influence well-being, namely health treatment program, health related information and complementary health related activities. In particular, we conceptualize health treatment programs as covering activities such as complying with basics and co-producing; health related information as including colearning and collating; and complementary health related activities as including diet and exercise, change and distracting. Clearly, practices go beyond medical activities such as adhering to medical advice (Seiders et al., 2015) and confirm that health care customers perform a wide range of activities (McColl-Kennedy et al., 2012).

We extend the scope of cocreative customer practices beyond the firm - customer dyad to other individuals in the customer's service network demonstrating that health care customers interact with medical staff at the medical center, other customers, and friends and family. However, the relative impact of the different interactions and activities on well-being could not be determined from this study, so a conceptual model and hypotheses is developed and tested in Studies 2 and 3.

\section{Conceptual Model and Hypotheses}

Consistent with our second objective we developed the conceptual model shown in Figure 1 based on our literature review and preliminary evidence from the diary study (Study 1). There are two assumptions: (1) maximizing an individual's perceived well-being is a key goal in health care; and (2) value is realized through interactions and activities (McColl-Kennedy et al., 2012). In this model customer value cocreation interactions are posited to affect customer value cocreation activities, which in turn affect an individual's well-being. Interactions can take place with the focal firm (medical doctors at the medical center in the present case), but also through interactions with others, for example, friends and family, or other customers (McColl-Kennedy 
et al., 2012). In the following section we present our hypotheses. We first discuss interactions with the medical staff, then with other customers, and then with friends and family with links to activities, and then how activities are linked to well-being.

- Insert Figure 1 about here -

\subsection{Health care interactions}

In health care, interactions between health care customers and medical staff play a key role. Importantly, interpersonal interactions with medical staff increases open communication facilitating the doctor's ability to enact social elements such as trust, concern, and empathy with the health care customer (Hausman, 2004). Framed within the broaden-and-build theory of positive emotions, Gallan et al. (2013) find that when a customer experiences greater levels of positivity, the customer engages in activities such as actively sharing information, providing suggestions, and engaging in shared decision-making. Interactions between medical staff and the customer provide opportunities for communication of essential information between the two parties and coproduction of positive outcomes (Hausman, 2004; Street et al., 2009). Hence:

H1. Interactions with medical staff (doctors) at the medical center have a positive effect on coproduction.

Compliance, or adherence, defined as "the degree to which health care customer behavior coincides with medical advice”, is regarded as a cornerstone in medical science (Lutfey, 2004, p. 343). The vast majority of research within health care has focused on individuals' deviant behavior, or noncompliance (Camacho et al., 2014), and the ways in which this behavior can be changed (Bissell et al., 2004; Lutfey, 2004). However, compliance with medical treatment regimens is suggested to be the result of social processes such as interpersonal elements during health care customer interactions with medical practitioners, not simply as a result of the medical practitioners' unilateral instructions for a treatment plan (Hausman, 2004; Lutfey, 2004). 
Interpersonal elements, such as support and encouragement, are found to increase compliance, suggested to be elicited over time through the development of positive affective reactions (Seiders et al., 2015). We thus posit that a higher level of interaction with medical staff will lead to higher levels of compliance with basics. Hence:

H2. Interactions with medical staff (doctors) at the medical center have a positive effect on compliance with basics.

Interpersonal elements, such as positive relational interactions, are found to elicit open communication and trust (Leisen \& Hyman, 2004; Hausman, 2004; Seiders et al., 2015). Interpersonal interaction facilitates formal and informal information-sharing and acts as a tool to enable the transmission of meaningful and timely information. On the other hand, lower levels of physician-customer social interaction is found to interfere with the ability to cope with anxiety, make informed decisions, and learn about their medical condition (Tran et al., 2004). Therefore: H3. Interactions with medical staff (doctors) at the medical center have a positive effect on colearning activities.

Interactions with other customers with a similar ongoing illness provides customers with a source of information, other than the customer's physician. Cognitive processes occur during social interaction, such as through verbal elaboration where group members ask questions and explain their reasoning for solutions. Prior research suggests that help-seeking and help-giving through verbal elaboration contributes to the learning for both the help-seeker and giver (Olivera \& Straus, 2004). More recent research suggests that the ability to communicate with other customers has a positive impact on learning (Dholakia et al., 2009). Learning through interactions with other customers provides not only social benefits, but valuable "know how", thus enabling individuals to share their knowledge and expertise (Dholakia et al., 2009). Hence: H4. Interactions with other customers have a positive effect on colearning activities. 
A longitudinal study by Ramírez et al. (2013) sought to identify the effects of various information sources on health-related behaviors. Findings suggest that the effects of collating information from interpersonal and media sources predicts positive health behaviors (i.e., fruit and vegetable consumption and exercise) above and beyond the influence of seeking information from a health care customer's physician (Ramírez et al., 2013). Therefore, we argue that:

H5. Interactions with friends and family have a positive effect on collating activities.

Engaging in social interactions through leisure activities is suggested to have numerous beneficial outcomes, including relaxation and stress relief, and helps individuals meet personal goals related to well-being (Cahow et al., 2012). Findorff et al. (2007) find that individuals who lack confidence in their ability to engage in health-related activities are more easily deterred by obstacles and setbacks. However, Franks et al. (2012) find that individuals who engage in social interactions with friends and family, and share communication about strategies and plans to enact decisions in healthful behaviors, gain confidence in their own ability to make changes to their lifestyle. Cahow et al. (2012) investigating therapeutic recreation for customers with traumatic spinal cord injury, demonstrate that greater participation in social interaction through community events enables diversional and leisure activities with multiple positive outcomes. Thus, we posit that:

H6a. Interactions with friends and family have a positive effect on diet and exercise. H6b. Interactions with friends and family have a positive effect on changing behavior. H6c. Interactions with friends and family have a positive effect on distracting activities.

\subsection{Health care activities}

The "patient-centered" approach takes into account the active role of customers responsible for their day-to-day health care management, thereby shifting responsibility from health care professionals to the individual (Barlow et al., 2002). It seeks to harness the experiential knowledge customers amass over the course of their illness (Barlow et al., 2002). 
The idea of "lay expertise” suggests that over time customers gain a level of mastery in understanding their own specific medical condition (Bissell et al., 2004). Acknowledging that customers can be more aware of their specific individual circumstances than the physician, and encouraging them to take an active role in the management of their treatment plan, engenders self-efficacy in the customer that helps them implement their own plans and achieve their goals (Michie et al., 2003). Indeed, Guo et al. (2013) find that as customers develop a level of mastery and insight into their own medical condition, and which prescribed treatments and medications do and do not work best for them, higher levels of coproduction and well-being are elicited. Therefore, we posit that:

H7. Complying with basics is positively related to coproduction.

Interpersonal elements, such as positive relational interactions and open communication have been shown to affect health care customer compliance (Hausman, 2004). Sharing information, providing feedback, and asking questions of the physician, provides a means by which the physician can ensure that the health care customer has a clear understanding of their role. Role clarity is found to have a positive effect on customers' compliance (Guo et al., 2013). This is suggested to be a result of the customer having a more precise understanding of what is required of them. Hence, clarity in behavioral requirements through sharing information, asking questions and providing feedback (i.e., colearning), guides behavior and knowledge about appropriate conduct. Thus, we argue that:

H8. Colearning is positively related to compliance with basics.

In a longitudinal study of cancer patients, health-related information-seeking through multiple sources, including friends and family, is found to positively influence diet, exercise, fruit and vegetable consumption, and a change in lifestyle behaviors (Moldovan-Johnson et al., 2014). Through social interaction, information obtained motivates further information-seeking 
behavior with subsequent positive health behaviors through support from social networks (Lewis \& Martinez, 2014). Interestingly, seeking and collating information predicts healthy behaviors, such as making lifestyle changes (Ramírez et al., 2013).

Within the framework of the transactional model of stress and coping, Parelkar et al. (2013) examine the relationship between cancer survivors' efforts to manage stress and make changes to health behaviors across various lifestyle behavior domains. Findings indicate that cancer survivors who engaged in stress control activities, such as through distraction, were more likely to make changes in their physical, psychosocial and preventive health behaviors. As previously discussed, involvement in hobbies and leisure activities is found to have many beneficial outcomes, such as enabling individuals to control stress and engage in active coping strategies (i.e., distraction and activity management) with subsequent positive lifestyle changes (Cahow et al., 2012). Thus, we posit that:

H9a. Collating information is positively related to diet and exercise.

H9b. Diet and exercise is positively related to changing behavior.

H9c. Distracting activities are positively related to changing behavior.

\subsection{Well-being}

Where customers take an active role and develop a level of mastery in managing their ongoing illness, over time higher levels of self-efficacy are elicited (Guo et al., 2013). Moreover, supporting patients' independence to actively manage their own illness has positive effects on health outcomes over and above patients' adherence to specific advice given by their physician (Michie et al., 2003). Hence, it is hypothesized that as levels of compliance with basics are subsumed by higher levels of coproduction, higher levels of well-being will be evidenced. H10a. Coproduction activities have a positive effect on well-being. 
Considerable research on intervention trials supports the benefits of healthy eating and exercise on positive health-related outcomes, such as improved well-being, reduced depression, reduced cancer-related fatigue and the prevention or minimization of treatment-related side effects (Wolin et al., 2013). Furthermore, research supports the effects of participation in leisure, community and diversional activities, on multiple positive outcomes, such as making life changes and well-being outcomes (Cahow et al., 2012). As such, we argue that:

H10b. Diet and exercise has a positive effect on well-being. H10c. Changing behavior has a positive effect on well-being.

No direct relationship is hypothesized between compliance and well-being. Indeed, McColl-Kennedy et al. (2012) found that health care customers, who strictly comply with the basics, do not engage in more effortful coproduction or self-generated activities, and evidenced low well-being. No relationship is hypothesized from health related information (i.e., colearning and collating) to well-being. Rather, as discussed previously, these activities support an individual's health treatment program activities and complementary health related activities.

\section{Study 2}

\subsection{Estimation of model and test of hypotheses}

Prior to Study 2 we undertook a pre study to develop measures and validate our measurement model. Measures were developed from the literature review and the diary study (Study 1) and are provided in Appendix 1. Following convention (Churchill, 1979) assessment of reliability and construct validity was undertaken for the interactions, activities, and well-being scales and their structure using exploratory and confirmatory factor analyses. (See the Web Appendix for details.)

The purpose of Study 2 is to test the hypotheses and investigate the effects of customer value cocreation practices (interactions and activities) on well-being. We obtained our sample of 
250 adults with an ongoing illness through a professional market research company. . The average age is 44.8 years, $49 \%$ being female. Six percent indicated that they attended a medical center on average once a week, $26 \%$ attended a medical center monthly, and $68 \%$ attended a medical center on a yearly basis, see Web Appendix for further details.

\subsection{Method}

We used the survey instrument developed in the pre study for interactions, activities and well-being (28 items for customer value co-creation practices and 13 items for well-being listed in Appendix 1). In addition, we included questions on how often the health care customers visit the medical center and how long they have had the ongoing illnesses. We apply PLS (Fornell \& Cha, 1994; Hulland, 1999) to estimate our conceptual model. The use of PLS is motivated by the small data set, the complex model and our objective to explain how interactions and activities affect well-being (Hair et al., 2011). Specifically, we employ SMARTPLS (Ringle et al., 2015) that enables testing of hypotheses with multi-item measurement using reflective scales (Fornell \& Bookstein, 1982; Hair et al., 2012). As shown in Figure 1, our conceptual model comprises three latent constructs for the different types of interactions with medical staff, other customers, and friends and family, seven latent constructs to address different types of activities (coproduce, comply with basics, colearn, collate, diet and exercise, change and distract), and one latent constructs for the outcome, i.e. well-being. All latent variables are measured using multiple items as reflective constructs.

The reliability and validity of the measurement model was tested (Fornell \& Larcker, 1981). All items loaded appropriately on their respective constructs, and all loadings reached the recommended level of .70 (Hair et al., 2012; Hulland, 1999). In addition, the loadings, Cronbach alphas and composite reliabilities were higher than the recommended threshold of .70 (Hair et 
al., 2011), and the AVEs higher than the suggested threshold of .50 (Fornell \& Larcker, 1981). In order to ensure discriminant validity of the constructs, the AVEs of the latent constructs were compared to the square of the correlations among them (Chin, 1998). See Table 3. The measurement model demonstrated discriminant validity (Hair et al., 2012).

- Insert Table 3 about here -

\subsection{Results}

We list the path coefficients, significance levels and confidence intervals in Table 4. The model explains $25 \%$ of perceived well-being for the health care customers. The model provides predictive relevance as indicated by the Stone-Geisser's $Q^{2}\left(Q^{2}=0.143\right)$ being positive and larger than 0 (Henseler et al., 2009). All relationships in the model except one, show a statistically significant relationship in the hypothesized directions. There is a significant positive relationship between interactions with medical staff (doctors) at the medical center and activities associated with coproduction $(\mathrm{H} 1: \beta=.34 ; \mathrm{p}<.01)$, compliance with the prescribed treatment regime (H2: $\beta=.44 ; \mathrm{p}<.01)$ and colearning activities $(\mathrm{H} 3: \beta=.50 ; \mathrm{p}<.01)$. A positive and significant relationship was found between interactions with other health care customers and colearning activities (H4: $\beta=.17 ; p<.01)$. We found a significant positive relationship between interactions with friends and family and collating information $(\mathrm{H} 5: \beta=.49 ; \mathrm{p}<.01)$, maintaining a healthy diet and exercise plan (H6a: $\beta=.29 ; \mathrm{p}<.01)$, changing activities to manage the ongoing health situation (H6b: $\beta=.25 ; \mathrm{p}<.01$ ), and activities associated with distracting oneself from thinking about the medical condition (H6c: $\beta=.42 ; \mathrm{p}<.01)$.

- Insert Table 4 about here -

Certain activities appear to be linked. We found a significant positive relationship between compliance and coproduction activities $(\mathrm{H} 7: \beta=.56 ; \mathrm{p}<.01)$, as well as between 
colearning and compliance activities $(\mathrm{H} 8: \beta=.31 ; \mathrm{p}<.01)$. A significant positive relationship was also found between collating information, and activities associated with maintaining a healthy diet and exercise plan (H9a: $\beta=.39 ; \mathrm{p}<.01)$. Activities associated with maintaining a healthy diet and exercise plan (H9b: $\beta=.29 ; \mathrm{p}<.01)$ and activities associated with distracting oneself (H9c: $\beta=.38 ; \mathrm{p}<.01$ ) from thinking about the medical condition, were both positively and significantly linked to changing activities to manage the ongoing health situation.

Finally, both coproduction (H10a: $\beta=.23 ; \mathrm{p}<.01)$ and diet and exercise $(\mathrm{H} 10 \mathrm{~b}: \beta=.43$; $\mathrm{p}<.01$ ) were positively and significantly linked to well-being. The only exception is H10c that shows a negative non-significant relationship between change and well-being (H10c: $\beta=-.12$; $\mathrm{p}>.10)$.

\subsection{Study 2 Implications}

In summary, we find support for all but one of the hypothesized relationships (H10c) in the conceptual model linking customer practices (interactions and activities) to well-being. In general, interactions with medical staff (doctors), other customers, and friends and family contribute to health treatment programs, health related information, and complementary health related activities which improve well-being. In particular, coproduction and diet and exercise have a direct effect on well-being. Interestingly, organizing one's life to fit around the specific health situation does not improve well-being. To further investigate the relative effects of different interactions and activities on well-being, we now examine how these effects vary across different ongoing illness contexts.

\section{Study 3}

The purpose of Study 3 is to test the model across three ongoing illnesses, investigating how stable the effects of interactions and activities are on well-being. We further use three 
independent samples of health care customers representing three major ongoing illnesses: cardiovascular ( $n=257)$, musculoskeletal $(n=138)$, and psychological illnesses $(n=235)$ to test the stability as well as limits of the conceptual model. The three samples display a similar pattern with most health care customers belonging to the 50 to 59 years age group. However, in the cardiovascular sample there are more men (60\%), while the percentages for musculoskeletal and psychological illnesses are $47 \%$ and $46 \%$, respectively, see Web Appendix.

\subsection{Method}

The same items used in Study 2 are employed in Study 3. (See Appendix 1.) All constructs display convergent validity (Table 3). AVEs are greater than .5 (Fornell \& Larcker, 1981). There is high internal consistency reliability with composite reliability $\geq .70$ (Bagozzi \& Yi, 1988), and good reliability with Cronbach alphas $\geq .70$ (Nunnally \& Bernstein, 1994). In addition, the Fornell-Larcker criterion for discriminant validity is fulfilled with each construct's AVE being higher than its squared correlation with any other construct (Fornell \& Larcker, 1981). As in Study 2, we apply PLS using SMARTPLS (Ringle et al., 2015) to estimate the models for the three illness contexts.

\subsection{Results}

We provide path coefficients, significance levels and confidence intervals in Table 4. The model explains $14.8 \%, 14.5 \%$ and $16.7 \%$ of perceived well-being for health care customers with cardiovascular, musculoskeletal, and psychological illnesses, respectively. The StoneGeisser's $Q^{2}$ for each model is positive and larger than 0 (Henseler et al., 2009). Forty-four out of forty-eight relationships in the three models show a statistically significant relationship. Of the hypotheses suggesting that interactions and activities are interrelated, all but one relationship is supported. The unsupported path concerns the relationship between interaction with other 
customers and colearn (H4: $\beta=.05 ; \mathrm{p}>.10)$ for health care customers with psychological illnesses. The other hypotheses, H1 to H3 and H5 to H9 are supported for all three samples.

For H10 (a,b,c), i.e. how coproduction, diet and exercise, and change influence wellbeing, we find that the effect appears to differ depending on the type of ongoing illness. For the cardiovascular sample, we find that coproduction (H10a: $\beta=.18 ; \mathrm{p}<.05)$ and diet and exercise (H10b: $\beta=.36 ; p<.01$ ) are positively and significantly linked to well-being. However, change shows a negative statistically significant relationship with well-being (H10c: $\beta=-.26$; $p<.05$ ). For the musculoskeletal sample, we find no support for the relationship between coproduction and well-being (H10a: $\beta=-.03 ; p^{>} .10$ ), while diet and exercise is positively and significantly linked to well-being (H10b: $\beta=.44 ; p<.01)$. However, change once again shows a negative statistically significant relationship with well-being (H10c: $\beta=-.25 ; \mathrm{p}<.01)$. Finally, for the sample of health care customers with psychological illnesses, only change has a positive statistically significant relationship with well-being (H10c: $\beta=.36$; $\mathrm{p}<.01$ ). However, we find no support for the relationship between coproduction (H10a: $\beta=-.08 ; \mathrm{p}>.10)$, diet and exercise (H10b: $\beta=.14 ; \mathrm{p}>.10)$ and well-being, respectively.

\subsection{Study 3 Implications}

The main implication is that certain customer practices do not always lead to improved well-being. Results show that certain customer practices have opposite effects depending on the illness. Change has different effects on well-being in cardiovascular, musculoskeletal and psychological ongoing illnesses. We found a change of signs for the effect of changing behavior on well-being from negative for the cardiovascular $(\beta=-.26 ; \mathrm{p}<.05)$ and musculoskeletal illness samples $(\beta=-.25 ; \mathrm{p}<.01)$ to positive for the psychological illness sample $(\beta=.36 ; \mathrm{p}<.01)$.

\section{Conclusion}


Even if people consider health related activities important and have good intentions to comply with treatment and change their behaviors to fit their current health situation, a majority reports difficulties in consistently performing those behaviors (Finberg, 2013). Based on SelfRegulation Theory (Bandura, 1991), Ryan and Deci (2000) suggest that even though the relationship between goals and well-being is theorized to be invariant, the question of how specific goals relate to well-being can vary across contexts. For example, well-being is influenced by the individual's motivation for performing a specific activity. Some activities are performed in order to reach an outcome that is separated from the activity, while others are performed for the inherent satisfaction of the activity itself (Ryan \& Deci, 2000). That is, for an individual to function effectively, he or she must have the ability to resist the temptation of smaller but more immediate rewards in order to receive a larger or more enduring reward at a later time. When the activities and their effects are separated in time they exert a disproportionate attraction (Hoch \& Loewenstein, 1991).

In health related activities, the success and reward of preventing and managing illness is often invisible or significantly delayed, and requires persistent behavioral changes (Fineberg, 2013). For example, smoking a cigarette can give relief and increase well-being short-term, but has a long-term negative effect on the individual's health. In chronic and ongoing illnesses, the customer is given complex tasks to be repeatedly performed over a long period of time, and often these activities are unwanted (Spanjol et al., 2015). These health related changes in behavior might not immediately lead to a positive effect on well-being. Further, in some cases they can result in a temporarily decrease in well-being. Therefore, in illnesses where changes are connected to instant rewards, there is likely to be a positive effect of changing behavior. In contrast, for illnesses where the reward is delayed, for example, where a health care customer has 
to give up a desired behavior, such as eating unhealthy food, or a convenience-focused lifestyle, negative effects on well-being are likely.

Consistent with Construal Level Theory (Trope \& Liberman, 2010), Stephan et al. (2010) suggest that interactions and activities with individuals of short psychological distance (such as family and friends) should be more likely, than with those who are considered more psychologically distant. Not only are these interactions and activities more likely to occur, they also are likely to have a larger effect on health care customers' well-being than interactions and activities with medical staff and other health care customers. In particular, customer-directed activities such as diet and exercise and change can have a significant effect on well-being. This can be explained by the shorter psychological distance, and the effects can be either in a positive or negative direction.

Our results show the criticality of involving friends and family in activities to improve well-being. However, the results do not suggest that interactions and activities with medical staff should be reduced or replaced by customer-directed activities. Instead, they should be regarded as complementary. Importantly, if interactions and activities with medical staff are supplemented with customer-directed activities the total effect on well-being is stronger.

\subsection{Theoretical implications}

Our research makes an important contribution to two service research priorities - better understanding the process of value creation and well-being (Ostrom et al., 2015) in three important ways. First, using Self-regulation Theory and Construal Level Theory together with Practice Theory, we are able to explain the complex relationships between interactions, activities and well-being. Our study is the first to unpack which specific activities, in interactions with whom (medical professionals, other customers or friends and family), have the greatest impact 
on well-being across major ongoing illness contexts. While the pioneering work of McCollKennedy et al. (2012) explored a range of customer interactions and activities and suggested links to quality of life, their work was confined to a qualitative investigation in one chronic illness - cancer.

Our study makes a second contribution by developing and validating a customer value cocreation practices scale that is robust across four ongoing illnesses contexts. While Sweeney et al. (2015) provide an important contribution, demonstrating a hierarchy of value cocreation activities, such that some activities are more effortful than others, and that customer Effort in Value Cocreation Activities (EVCA) is linked to quality of life, our work extends their contribution by demonstrating the relative impact of specific customer interactions and activities on a more comprehensive measure of well-being.

Further, we show that while positive interactions with medical staff (doctors) lead to increased likelihood of complying with basics, which in turn leads to increased coproduction and increased well-being, other more customer-directed sets of practices have an even greater impact on well-being. Specifically, positive interactions with friends and family lead to collating and undertaking complementary activities (diet and exercise), which in turn leads to enhanced wellbeing. Interestingly, although we find in the psychological illness context, changing behavior can have a positive influence on well-being, changing behavior is not generally linked to well-being. This can be explained through individuals being reluctant to change the level and type of activities they undertake in order to better manage their life now given their illness, such as having to take longer to undertake some tasks due to the pain, not eating certain foods, stopping smoking, and reducing alcohol consumption.

\subsection{Managerial implications}


The results of this research provide several implications for health care service managers and providers. First, this research highlights the criticality of recognizing the importance of customer interactions and activities on perceived well-being. Medical professionals can no longer expect to be seen as the only source of knowledge about how to enhance their patients' well-being. Health care customers input into their own health treatment plans is vital and should be encouraged. Especially trying to understand, from the individual patient's perspective, what would work best for that individual's own life situation is imperative.

Second, it is critical for health professionals to work with their customers to identify the set of practices most suited to the individual customer in order to maximize well-being. In particular, focusing on encouraging health care customers to engage in activities with their friends and family, collating information from the doctor and with other providers such as alternative therapies, distracting through undertaking time out with their family, engaging in hobbies, gardening, travel, and so on, and through diet and exercise, because these cocreative customer practices consistently impact positively on well-being.

Third, change is generally not viewed positively. Change means disruption to normal routines and often giving up old pleasures. But a "no pain, no gain” mantra should be encouraged in order to reach longer term well-being goals and so individuals need to be supported and rewarded particularly during the short to medium term in order to realize long term benefits.

\subsection{Future research}

Our findings show support for our conceptual model and the predicted relationships. However, like any research, we acknowledge some limitations that must be taken into consideration when interpreting the results. First, we examine cocreative practices from a health care customer perspective. A health care customer is a resource integrator, applying a unique set 
of skills and resources to improve their well-being. Health care customers, who suffer from specific combinations of illness, pain, uncertainty and fear, might not be willing to engage in certain interactions and activities. In addition, the customer is not the sole actor in this process. In forthcoming studies, a broader team including medical staff, other customers and friends and family can be used to triangulate data on customer value cocreation practices. This would provide a better understanding of the roles of the different participants and the respective outcomes for each participant in the value cocreation process.

Second, future research could investigate the relative influence of each of the key participants in the decision making process; in particular the role of goals in influencing multidimensional multiparty choices should be investigated. Previous research on consumer choice provides insight into individual level goal setting, assuming that decisions are made based on an individual's personal attitudes, beliefs and preferences. Yet existing theories do not adequately account for the many sociocultural consumption factors that go beyond explaining compliance (Xie et al., 2008).

Third, although we have used six different samples of health care customers in this research, each sample is studied at one point in time. While this provides a good understanding for how different interactions and activities influence well-being, there might be temporal effects of certain interactions and activities, i.e., that a certain activity has one effect in a certain phase of the care process while the effect might change in another phase. Longitudinal studies of health care customers, where interactions and activities as well as perceived well-being are tracked over time, should bring additional insights into how specific activities can have differential effect across health care customers, illnesses and time. We encourage others to undertake work along these potentially fruitful avenues of research. 


\section{References}

Agency for Healthcare Research and Quality (2014). Multiple chronic conditions chartbook. Retrieved June 13, 2014 from http://www.ahrq.gov/professionals/prevention-chroniccare/decision/mcc/mccchartbook.pdf.

Anderson, L., \& Ostrom, A. L. (2015). Transformative service research advancing our knowledge about service and well-being. Journal of Service Research, 18(3), 243-249.

Anderson, L., Ostrom, A.L., Corus, C., Fisk, R.P., Gallan, A.S., Giraldo, M., Mende, M., Mulder, M., Rayburn, S.W., Rosenbaum, M.S., Shirahada, K. \& Williams, J.D. (2013), "Transformative service research: An agenda for the future", Journal of Business Research, 66 (8), 1203-1210.

Bagozzi, R. P., \& Yi, Y. (1988). On the evaluation of structural equation models. Journal of the Academy of Marketing Science, 16(1), 74-94.

Bandura, A. (1991). Social cognitive theory of self-regulation. Organizational Behavior and Human Decision Processes, 50(2), 248-287.

Barlow, J., Wright, C., Sheasby, J., Turner, A., \& Hainsworth, J. (2002). Self-management approaches for people with chronic conditions: A review. Patient Education and Counseling, 48(2), 177-187.

Berry, L., \& Bendapudi, N. (2007). Health care: A fertile field for service research. Journal of Service Research, 10(2), 111-122.

Bissell, P., May, C. R., \& Noyce, P. R. (2004). From compliance to concordance: Barriers to accomplishing a reframed model of health care interactions. Social Science and Medicine, 58(4), 851-862.

Cahow, C., Gassaway J., Rider, C., Joyce, J. P., Bogenschutz, A., Edens, K., Kreider, S. E. D., \& Whiteneck, G. (2012). Relationship of therapeutic recreation inpatient rehabilitation interventions and patient characteristics to outcomes following spinal cord injury: The SCIRehab project. The Journal of Spinal Cord Medicine, 35(6), 547-564.

Camacho, N., De Jong, M., \& Stremersch, S. (2014). The effect of customer empowerment on adherence to expert advice. International Journal of Research in Marketing, 31(3), 293-308.

Cegala, D. J., Street Jr., R. L., \& Randall, C. (2007). The impact of patient participation on physicians' information provision during a primary care medical interview. Health Communication, 21(2), 177-185.

Centers for Medicare and Medicaid Services, National Health Expenditure Data, Projected. Retrieved June 9, 2015 from http://www.cms.gov/Research-Statistics-Data-andSystems/Statistics-Trends-andReports/NationalHealthExpendData/NationalHealthAccountsProjected.html.

Chin, W. W. (1998). The partial least squares approach to structural equation modeling. In G. A. Marcoulides (Eds.), Modern methods for business research (pp. 295-336). New Jersey: LEA.

Churchill Jr., G. A. (1979). A paradigm for developing better measure of marketing constructs. Journal of Marketing Research, 16(1), 64-73.

Cohen, R., Hassan, A., Lapointe, B. J., \& Mount, B. M. (1996). Quality of life in HIV disease as measured by the McGill quality of life questionnaire. AIDS, 10(12), 1421-1427.

Diener, E., Oishi, S., \& Lucas, R. E. (2003). Personality, culture, and subjective well-being: Emotional and cognitive evaluations of life. Annual Review of Psychology, 54(1), 403-425.

Diener, E., Suh, E., Lucas, R. E., \& Smith, H. L. (1999). Subjective well-being: Three decades of progress. Psychological Bulletin, 125(2), 276-302. 
Dholakia, U. M., Blazevic, V., Wiertz, C., \& Algesheimer, R. (2009). Communal service delivery: How customers benefit from participation in firm-hosted virtual P3 communities. Journal of Service Research, 12(2), 208-226.

Elg, M., Engström, J., Witell, L., \& Poksinska, B. (2012). Co-creation and learning in health-care service development. Journal of Service Management, 23(3), 328-343.

Fineberg, H. V. (2013). The paradox of disease prevention: Celebrated in principle, resisted in practice. The Journal of the American Medical Association, 310(1), 85-89.

Findorff, M. J., Hatch Stock, H., Gross C. R., \& Wyman, J. F. (2007). Does the transtheoretical model (TTM) explain exercise behavior in a community-based sample of older women? Journal of Aging and Health, 19(6), 985-1003.

Fornell, C. G., \& Bookstein, F. L. (1982). Two structural equation models: LISREL and PLS applied to consumer exit-voice theory. Journal of Marketing Research, 19(4), 440-452.

Fornell, C. G., \& Cha, J. (1994). Partial least squares. In R. P. Bagozzi (Ed.), Advanced methods of marketing research (pp. 52-78). Cambridge, MA: Blackwell.

Fornell, C. G., \& Larcker, D. F. (1981). Evaluating structural equation models with unobservable variables and measurement error. Journal of Marketing Research, 18(1), 39-50.

Franks, M. M., Shields, C. G., Lim, E., Sands, L. P., Mobley, S., \& Boushey, C. J. (2012). I will if you will similarity in married partners' readiness to change health risk behaviors. Health Education and Behavior, 39(3), 324-331.

Gallan, A. S., Burke Jarvis, C., Brown, S. W., \& Bitner, M.J. (2013). Customer positivity and participation in services: An empirical test in a health care context. Journal of the Academy of Marketing Science, 41(3), 338-356.

Guo, L., Arnould, E. J., Gruen, T. W., \& Tang, C. (2013). Socializing to co-produce pathways to consumers' financial well-being. Journal of Service Research, 16(4), 549-563.

Hair, J. F., Ringle C. M., \& Sarstedt, M. (2011). PLS-SEM: Indeed a silver bullet. Journal of Marketing Theory and Practice, 19(2), 139-152.

Hair, J. F., Sarstedt, M., Ringle, C. M., \& Mena, J. (2012). An assessment of the use of partial least squares structural equation modeling in marketing research. Journal of the Academy of Marketing Science, 40(3), 414-433.

Henseler, J., Ringle, C. M., \& Sinkovics, R. R. (2009). The use of partial least squares path modeling in international marketing. Advances in International Marketing, 20(1), 277-319.

Hausman, A. (2004). Modeling the patient-physician service encounter: Improving patient outcomes. Journal of the Academy of Marketing Science, 32(4), 403-417.

Hoch, S. J., \& Loewenstein, G. F. (1991). Time-inconsistent preferences and consumer selfcontrol. Journal of Consumer Research, 17(4), 492-507.

Hulland, J. (1999). Use of partial least squares (PLS) in strategic management research: A review of four recent studies. Strategic Management Journal, 20(2), 195-204.

Kjellberg, H., \& Helgesson, C-F. (2006). Multiple versions of markets: Multiplicity and performativity in market practice. Industrial Marketing Management, 35(2), 839-855.

Leisen, B., \& Hyman, M. R. (2004). Antecedents and consequences of trust in a service provider: The case of primary care physicians. Journal of Business Research, 57(9), 990-999.

Lewis, N., \& Martinez, S. (2014). Does the number of cancer patients' close social ties affect cancer-related information seeking through communication efficacy? Testing a mediation model. Journal of Health Communication, 19(9), 1076-1097.

Lutfey, K. (2004). Assessment, objectivity, \& interaction: The case of patient compliance with medical treatment regimens. Social Psychology Quarterly, 67(4), 343-368. 
McColl-Kennedy, J. R., Vargo, S. L., Dagger, T. S., Sweeney, J. C., \& van Kasteren, Y. (2012). Health care customer value cocreation practice styles. Journal of Service Research, 15(4), 370-389.

Michie, S., Miles, J., \& Weinman, J. (2003). Patient-centredness in chronic illness: What is it and does it matter? Patient Education and Counseling, 51(3), 197-206.

Mick, D. G., Pettigrew, S., Pechmann, C. C., \& Ozanne, J. L. (2012). Transformative consumer research: For personal and collective well-being. Taylor and Francis.

Mischel, W., Shoda, Y., \& Rodriguez, M. I. (1989). Delay of gratification in children. Science, 244(4907), 933-938.

Moldovan-Johnson, M., Martinez, L., Lewis, N., Freres, D., \& Hornik R. C. (2014). The role of patient-clinician information engagement and information seeking from nonmedical channels in fruit and vegetable intake among cancer patients. Journal of Health Communication, 19(12), 1359-1376.

Nunnally, J., \& Bernstein, I. (1994). Psychometric theory ( $3^{\text {rd }}$ ed.). New York: McGraw Hill.

Olivera, F., \& Straus, S. G. (2004). Group-to-individual transfer of learning cognitive and social factors. Small Group Research, 35(4), 440-465

Ostrom, A. L., Parasuraman, A., Bowen, D. E., Patrício, L., Voss, C. A., \& Lemon, K. (2015). Service research priorities in a rapidly changing context. Journal of Service Research, 18(2), 127-159.

Payne, A. F., Storbacka, K., \& Frow, P. (2008). Managing the co-creation of value. Journal of the Academy of Marketing Science, 36(1), 83-96.

Parelkar, P., Thompson, N. J., Kwei Kaw, C., Miner, K. R., \& Stein, K. D. (2013). Stress coping and changes in health behavior among cancer survivors: A report from the American cancer society's study of cancer survivors-II (SCS-II). Journal of Psychosocial Oncology, 31(2), 136-152.

Perreault, W. D., \& Leigh, L. E. (1989). Reliability of nominal data based on qualitative judgments. Journal of Marketing Research, 26(2), 135-148.

Podsakoff, P. M., MacKenzie, S. B., Paine, J.B., \& Bachrach, D. G. (2000). Organizational citizenship behaviors: a critical review of the theoretical and empirical literature and suggestions for future research. Journal of Management, 26(3), 513-563.

Ramírez, A. S., Freres, D., Martinez, L. S., Lewis, N., Bourgoin, A., Kelly, B. J., Lee, C.J., Nagler, R. J., Schwartz, S., \& Hornik, R. C. (2013). Information seeking from media and family/friends increases the likelihood of engaging in healthy lifestyle behaviors. Journal of Health Communication, 18(5), 527-542.

Reckwitz, A. (2002). Toward a theory of social practices: A development in culturalist theorizing. European Journal of Social Theory, 5(2), 243-263.

Ringle, C., Wende, S., \& Becker, J.M. (2015). SmartPLS3 (Version 3). Hamburg. Available from www.smartpls.com.

Rosenbaum, M.S. \& Smallwood, J. (2013), “Cancer resource centers as third places”, Journal of Services Marketing, 17(6), 472-484.

Rust, R. T., \& Cooil, B. (1994). Reliability measures for qualitative data: Theory and implications. Journal of Marketing Research, 31(1), 1-14.

Rust, R. T., \& Huang, M.H. (2014). The service revolution and the transformation of marketing science. Marketing Science, 33(2), 206-221.

Ryan, R. M., \& Deci, E. L. (2000). Self-determination theory and the facilitation of intrinsic motivation, social development, and well-being. American Psychologist, 55(1), 68-78. 
Schatzki, T. R. (2005). Peripheral vision: The sites of organizations. Organization Studies, 26(3), 465-484.

Seiders, K., Godfrey Flynn, A., Berry, L. L., \& Haws, K. L. (2015). Motivating customers to adhere to expert advice in professional services: A medical service context. Journal of Service Research, 18(1), 39-58.

Singh, J., Cuttler, L., \& Silvers, J. B. (2004). Toward understanding consumers' role in medical decisions for emerging treatments: Issues, framework and hypotheses. Journal of Business Research, 57(9), 1054-1065.

Spanjol, J., Cui, A. S., Nakata, C., Sharp, L. K., Crawford, S. Y., Xiao, Y., \& Watson-Manheim, M. B. (2015). Co-production of prolonged, complex, and negative services: An examination of medication adherence in chronically ill individuals. Journal of Service Research, 18(3), 284-302.

Stephan, E., Liberman, N., \& Trope, Y. (2010). Politeness and social distance: A construal level perspective. Journal of Personality and Social Psychology, 98(2), 268-280.

Street, R. L., Makoul, G. Jr., Neeraj, A. K., \& Epstein, R. M. (2009). How does communication heal? Pathways linking clinician-patient communication to health outcomes. Patient Education and Counseling, 74(3), 295-230.

Stremersch, S. (2008). Health and marketing: The emergence of a new field of research. International Journal of Research in Marketing, 25(4), 229-233.

Sweeney, J. C., Danaher, T. S., \& McColl-Kennedy, J. R. (2015). Customer effort in value cocreation activities improving quality of life and behavioral intentions of health care customers. Journal of Service Research, 18(3), 318-335.

Tran, A. N., Haidet, P., Street Jr., R. L., O’Malley, K. J., Martin, F., \& Ashton, C. M. (2004). Empowering communication: A community-based intervention for patients. Patient Education and Counseling, 52(1), 113-121.

Trope, Y., \& Liberman, N. (2010). Construal-level theory of psychological distance. Psychological Review, 117(2), 440-463.

Wagner, E. H., Bennett, S. M., Austin, B. T., Greene, S. M., Schaefer, J. K., \& Vonkorff, M. (2005). Finding common ground: Patient-centeredness and evidence-based chronic illness care. The Journal of Alternative and Complementary Medicine, 11(1), 7-15.

Wolin, K. Y., Dart, H., \& Colditz, G. A. (2013). Eight ways to stay healthy after cancer: An evidence-based message. Cancer Causes Control, 24(5), 827-837.

World Health Organization. Retrieved June 9, 2015 from http://www.who.int/countries/usa/en/

Xie, C., Bagozzi, R. P., \& Troye, S. V. (2008). Trying to prosume: Toward a theory of consumers and co-creators of value. Journal of the Academy of Marketing Science, 36(1), 109-122. 


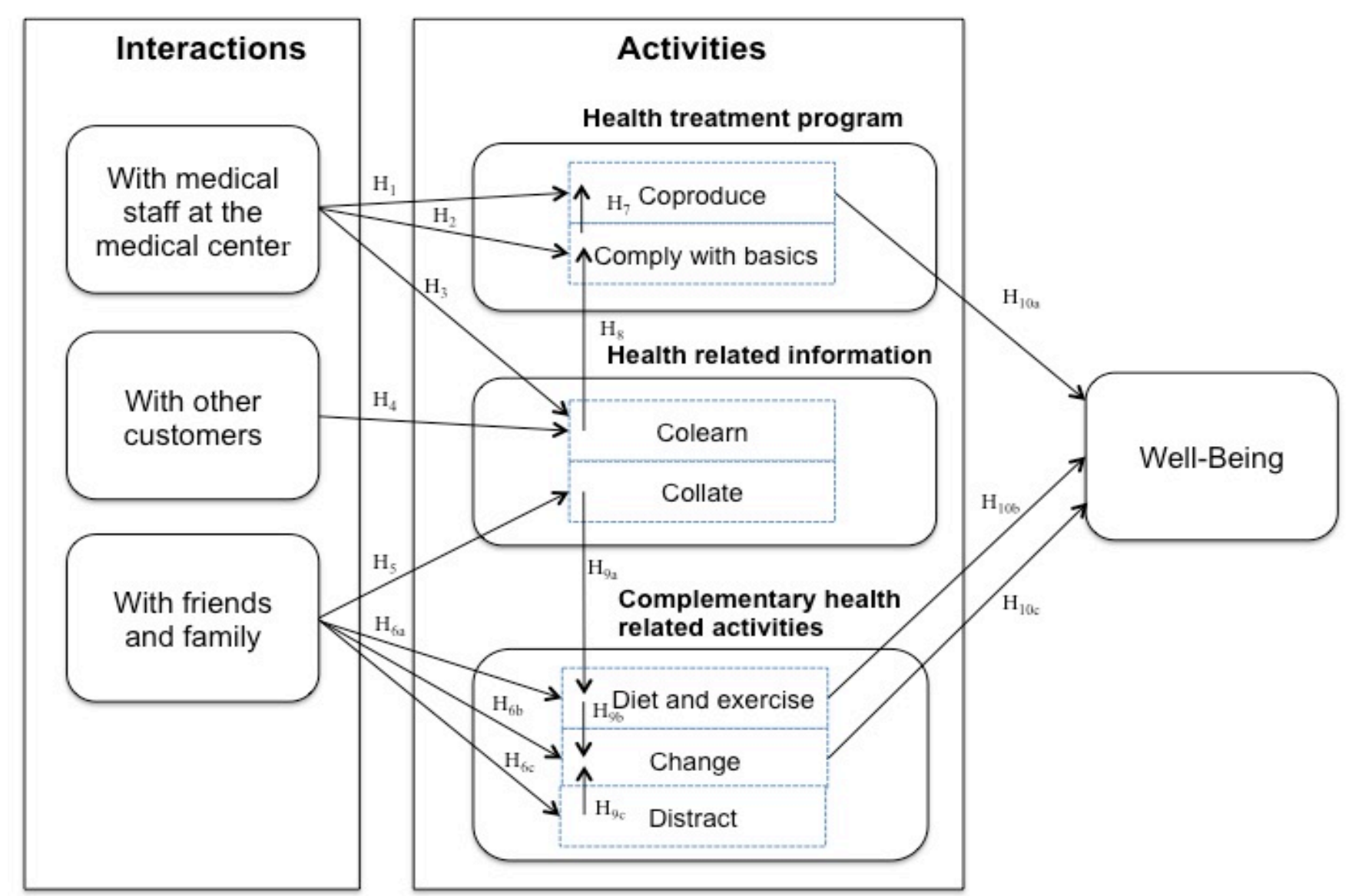

Figure 1. Health care customer cocreative practices model 
Table 1 Overview of studies

\begin{tabular}{|c|c|c|c|c|}
\hline 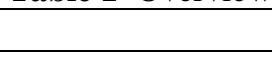 & Study 1 & Pre Study & Study 2 & Study 3 \\
\hline Purpose & $\begin{array}{l}\text { Identification and } \\
\text { categorization of } \\
\text { customer } \\
\text { interactions and } \\
\text { activities }\end{array}$ & $\begin{array}{l}\text { Scale development } \\
\text { and validation of } \\
\text { measurement model }\end{array}$ & $\begin{array}{l}\text { Estimation of } \\
\text { structural model } \\
\text { and test of } \\
\text { hypotheses }\end{array}$ & $\begin{array}{l}\text { Testing the } \\
\text { structural model } \\
\text { across three specific } \\
\text { illness contexts }\end{array}$ \\
\hline Method & Diary study & Survey & Survey & Survey \\
\hline \multirow[t]{2}{*}{ Data and context } & Qualitative & Quantitative & Quantitative & Quantitative \\
\hline & $\begin{array}{l}\text { Gastroenterology } \\
\text { and chronic pain }\end{array}$ & $\begin{array}{l}\text { Ongoing illnesses } \\
\text { e.g., hypertension, } \\
\text { arthritis, skin } \\
\text { conditions, stress, } \\
\text { chronic pain, } \\
\text { asthma }\end{array}$ & $\begin{array}{l}\text { Ongoing illnesses } \\
\text { e.g., hypertension, } \\
\text { arthritis, skin } \\
\text { conditions, stress, } \\
\text { chronic pain, } \\
\text { asthma }\end{array}$ & $\begin{array}{l}\text { Cardiovascular*, } \\
\text { Musculoskeletal **, } \\
\text { and Psychological } \\
\text { illnesses*** }\end{array}$ \\
\hline Analysis & Content analysis & $\begin{array}{l}\text { Exploratory and } \\
\text { Confirmatory factor } \\
\text { analysis }\end{array}$ & $\begin{array}{l}\text { Structural equation } \\
\text { modeling }\end{array}$ & $\begin{array}{l}\text { Structural equation } \\
\text { modeling }\end{array}$ \\
\hline Sample size $(n)$ & 20 & 251 & 250 & 630 \\
\hline
\end{tabular}


Table 2 Illustrative examples of cocreative practices identified in the diary study (Study 1)

\section{Health treatment program}

Comply with "Today I will take my first shot of Humira. I know I just have to take it.” (Anna, 30, gastroenterology) basics

$(n=17)$

"I can’t take my pills as often as every two hours; I would rather have four hours in between. But I want the pill in my body when I'm out of the house. (I have to eat when I take the pill or else I feel bad). But I take the medication as prescribed.” (Marie, 49, gastroenterology)

Coproduce $(n=12)$

"Talked to the doctor about the numbness in my left hand. He immediately wrote a referral to another hospital so they can take measurements of how the nerves in my hand are located. When we get the results we are going to discuss and put together a plan [for treatment].” (Elizabeth, 49, chronic pain)

“Today I've been exercising following the program the physiotherapist put together with me.” (Roger, 50, chronic pain)

\section{Health related information}

Colearn

$(n=24)$

Collate

$(n=10)$

"I could handle the pain for a while, but never again. The nurse comes in and tells me I don't have to do it anymore, no one should be in that kind of pain she says, 'it is almost like we both need to go to therapy after this'. It felt good to hear her say that. Instead I got two shots of cortisone in my foot.” (Karin, 54, chronic pain)

"Told her [the doctor] I feel really bad about all the different medical contacts. She understands and explains how their rehabilitation is done. There is a team of different doctors, physiotherapists, social workers etc. I thought that was absolutely wonderful.” (Sandra, 35, chronic pain)

"When you read on the Internet, you get partially conflicting answers. My quitting smoking has preceded both the present and first outbreak in 2004... I'm still in limbo about the effects of smoking." (Melvin, 39, chronic pain)

"Trying to read up on my condition a bit, but sometimes the medical staff don't believe you. Just because you have read it yourself.” (Sandra, 35, chronic pain)

\section{Complementary health related activities}

Diet and exercise $(n=23)$

Change $(n=50)$

Distract

$(n=9)$
"My stomach is working fine. Avoiding bread, it feels really good. Trying to only eat light food.” (Matilda, 31, gastroenterology)

"It's so nice to start the day by being in the pool. It feels good to have my personal program with exercises.” (Agnes, 30, chronic pain)

"I left my son a few hours in pre-school to take care of my sick daughter. It feels awful not being able to take care of both of them. ... Have to change the way I'm thinking ... If he is in pre-school a few hours he will play and have fun and when I pick him up I have more energy to take care of him.” (Agnes, 30, chronic pain)

"I'll try to learn to pause completely, without planning the grocery list or thinking about things I've forgotten. I'm slowly getting worse and I must try to reconcile myself with it.” (Johanna, 35, chronic pain)

“Everything hurts. I don’t even care about watching TV. Everything I do takes forever. I can’t find any comfort in my own body - I just want the day to end. Soon I will pick up my children - at least that will give me something else to think about [other than the pain].” (Johanna, 35, chronic pain)

"Made a nice dinner together with my husband. Was even motivated to pick herbs in the garden. My mood gets better by spending time with my family.” (Ann, 43, gastroenterology) 
Table 3 Discriminant validity assessment for Study 2 ( $n=250)$, and Study 3 Cardiovascular ( $n=257)$, Musculoskeletal ( $n=138)$ and Psychological illness ( $n=235$ )

\begin{tabular}{|c|c|c|c|c|c|c|c|c|c|c|c|}
\hline & 1. & 2. & 3. & 4. & 5. & 6. & 7. & 8. & 9. & 10. & 11. \\
\hline $\begin{array}{l}\text { 1. Interactions (with } \\
\text { medical staff) }\end{array}$ & $.94-.95$ & & & & & & & & & & \\
\hline $\begin{array}{l}\text { 2. Interactions (with } \\
\text { other customers) }\end{array}$ & $.40-.50$ & $.90-.91$ & & & & & & & & & \\
\hline $\begin{array}{l}\text { 3. Interactions (with } \\
\text { friends and family) }\end{array}$ & $.51-.62$ & $.58-.63$ & $.91-.93$ & & & & & & & & \\
\hline 4. Coproduce & $.65-.69$ & $.34-.40$ & $.42-.57$ & $.87-.91$ & & & & & & & \\
\hline 5. Comply & $.55-.70$ & $.10-.29$ & $.29-.50$ & $.63-.77$ & $.93-.95$ & & & & & & \\
\hline 6. Colearn & $.54-.65$ & $.28-.50$ & $.32-.49$ & $.57-.67$ & $.47-.63$ & $.93-.95$ & & & & & \\
\hline 7. Collate & $.40-.52$ & $.44-.61$ & $.41-.53$ & $.47-.52$ & $.16-.43$ & $.55-.74$ & $.89-.90$ & & & & \\
\hline 8. Diet and exercise & $.29-.47$ & $.26-.46$ & $.26-.48$ & $.30-.43$ & $.26-.34$ & $.21-.38$ & $.31-.53$ & $.86-.87$ & & & \\
\hline 9. Change & $.42-.53$ & $.47-.60$ & $.53-.57$ & $.48-.52$ & $.20-.46$ & $.44-.49$ & $.48-.58$ & $.41-.58$ & $.88-.90$ & & \\
\hline 10. Distract & $.30-.43$ & $.33-.48$ & $.42-.53$ & $.30-.41$ & $.16-.34$ & $.29-.35$ & $.33-.43$ & $.22-.39$ & $.54-.65$ & $.95-.96$ & \\
\hline 11. Well-being & $-.07-.29$ & $-.13-.36$ & $.05-.40$ & $0-.36$ & $0-.32$ & $-.14-.26$ & $-.14-.23$ & $.31-.47$ & $-.06-.40$ & $-.07-.16$ & $.74-.76$ \\
\hline \multicolumn{12}{|l|}{ Study 2} \\
\hline Mean(SD) & $4.59(1.93)$ & $3.54(2.18)$ & $4.57(1.93)$ & 4.97(1.89) & $5.20(1.81)$ & $4.57(2.09)$ & $3.96(2.02)$ & $4.84(1.72)$ & 4.4(1.99) & $4.68(1.82)$ & $6.31(2.35)$ \\
\hline AVE & 0.91 & 0.81 & 0.86 & 0.78 & 0.91 & 0.89 & 0.80 & 0.76 & 0.80 & 0.89 & 0.58 \\
\hline Cronbach alpha & 0.90 & 0.88 & 0.84 & 0.86 & 0.95 & 0.94 & 0.88 & 0.90 & 0.88 & 0.88 & 0.75 \\
\hline Composite reliability & 0.95 & 0.93 & 0.93 & 0.92 & 0.97 & 0.96 & 0.92 & 0.93 & 0.93 & 0.94 & 0.84 \\
\hline \multicolumn{12}{|l|}{ Cardiovascular } \\
\hline Mean(SD) & $4.5(2.00)$ & $2.88(1.97)$ & $4.15(2.00)$ & $4.61(2.05)$ & $5.51(1.71)$ & $4.08(2.22)$ & $3.14(1.90)$ & $4.65(1.68)$ & $3.8(2.02)$ & $3.8(2.04)$ & $6.34(2.30)$ \\
\hline AVE & 0.89 & 0.83 & 0.87 & 0.76 & 0.90 & 0.86 & 0.79 & 0.75 & 0.80 & 0.92 & 0.58 \\
\hline Cronbach alpha & 0.88 & 0.90 & 0.85 & 0.85 & 0.94 & 0.92 & 0.87 & 0.89 & 0.87 & 0.92 & 0.75 \\
\hline Composite reliability & 0.94 & 0.94 & 0.93 & 0.91 & 0.96 & 0.95 & 0.92 & 0.92 & 0.92 & 0.96 & 0.84 \\
\hline \multicolumn{12}{|l|}{ Musculoskeletal } \\
\hline Mean(SD) & $4.29(2.10)$ & $2.80(1.96)$ & $4.32(2.05)$ & $4.74(2.14)$ & $5.08(1.95)$ & $3.98(2.26)$ & $3.67(2.02)$ & $4.49(1.92)$ & $4.22(1.95)$ & 4.71(1.92) & $5.68(2.23)$ \\
\hline AVE & 0.91 & 0.82 & 0.84 & 0.83 & 0.90 & 0.89 & 0.78 & 0.75 & 0.79 & 0.92 & 0.55 \\
\hline Cronbach alpha & 0.90 & 0.89 & 0.80 & 0.89 & 0.95 & 0.94 & 0.86 & 0.89 & 0.87 & 0.92 & 0.72 \\
\hline Composite reliability & 0.95 & 0.93 & 0.91 & 0.93 & 0.97 & 0.96 & 0.92 & 0.92 & 0.92 & 0.96 & 0.83 \\
\hline \multicolumn{12}{|l|}{ Psychological } \\
\hline Mean(SD) & $4.60(1.96)$ & $2.88(1.97)$ & $4.15(2.00)$ & $4.76(1.99)$ & $5.27(1.75)$ & $4.41(2.20)$ & $3.45(1.95)$ & $4.21(1.81)$ & 4.36(1.89)( & $4.77(1.81)$ & $4.52(2.38)$ \\
\hline AVE & 0.88 & 0.82 & 0.86 & 0.78 & 0.86 & 0.87 & 0.79 & 0.76 & 0.78 & 0.91 & 0.56 \\
\hline Cronbach alpha & 0.87 & 0.89 & 0.84 & 0.86 & 0.92 & 0.93 & 0.87 & 0.89 & 0.86 & 0.90 & 0.77 \\
\hline Composite reliability & 0.94 & 0.93 & 0.92 & 0.91 & 0.95 & 0.95 & 0.92 & 0.93 & 0.91 & 0.95 & 0.83 \\
\hline
\end{tabular}


Table 4 Structural model estimation for Study $2(n=250)$, and Study 3 Cardiovascular $(n=257)$, Musculoskeletal ( $n=138)$ and Psychological illness $(n=235)$

\begin{tabular}{|c|c|c|c|c|c|c|c|c|}
\hline \multirow[b]{2}{*}{ Paths } & \multicolumn{2}{|c|}{$\begin{array}{c}\text { Study } 2 \\
\text { Ongoing illnesses }\end{array}$} & \multicolumn{2}{|c|}{$\begin{array}{c}\text { Study } 3 \\
\text { Cardiovascular }\end{array}$} & \multicolumn{2}{|c|}{$\begin{array}{c}\text { Study } 3 \\
\text { Musculoskeletal }\end{array}$} & \multicolumn{2}{|c|}{$\begin{array}{c}\text { Study } 3 \\
\text { Psychological } \\
\end{array}$} \\
\hline & $\begin{array}{c}\text { Path } \\
\text { coefficient }\end{array}$ & $\begin{array}{c}\text { Confidence } \\
\text { interval }\end{array}$ & $\begin{array}{c}\text { Path } \\
\text { coefficient }\end{array}$ & $\begin{array}{c}\text { Confidence } \\
\text { interval }\end{array}$ & $\begin{array}{c}\text { Path } \\
\text { coefficient }\end{array}$ & $\begin{array}{c}\text { Confidence } \\
\text { interval }\end{array}$ & $\begin{array}{c}\text { Path } \\
\text { coefficient }\end{array}$ & $\begin{array}{c}\text { Confidence } \\
\text { interval }\end{array}$ \\
\hline H1 Interactions (medical staff) $\rightarrow$ Coproduction & $.34^{* *}$ & [.192; .489] & $.43^{* *}$ & {$[.308 ; .550]$} & $.32^{* *}$ & {$[.201 ; .448]$} & $.45^{* *}$ & [.299; .598] \\
\hline $\begin{array}{l}\text { H2 Interactions (medical staff) } \rightarrow \text { Comply with } \\
\text { basics }\end{array}$ & $.44^{* *}$ & {$[.290 ; .589]$} & $.42^{* *}$ & {$[.293 ; .534]$} & $.51^{* *}$ & {$[.396 ; .614]$} & $.38^{* *}$ & {$[.258 ; .507]$} \\
\hline H3 Interactions (medical staff) $\rightarrow$ Colearn & $.50^{* *}$ & [.366; .639] & $.47^{* *}$ & {$[.347 ; .585]$} & $.53^{* *}$ & {$[.417 ; .633]$} & $.59^{* *}$ & {$[.475 ; .700]$} \\
\hline H4 Interactions (others) $\rightarrow$ Colearn & $.17^{* *}$ & {$[.047 ; .301]$} & $.17^{* *}$ & {$[.062 ; .285]$} & $.25^{* *}$ & {$[.138 ; .360]$} & .05 n.s. & {$[.005 ; .181]$} \\
\hline H5 Interactions (friends and family) $\rightarrow$ Collate & $.49^{* *}$ & {$[.376 ; .605]$} & $.42^{* *}$ & {$[.313 ; .528]$} & $.53^{* *}$ & {$[.430 ; .620]$} & $.41^{* *}$ & {$[.303 ; .524]$} \\
\hline $\begin{array}{l}\text { H6a Interactions (friends and family) } \rightarrow \text { Diet and } \\
\text { exercise }\end{array}$ & $.29^{* *}$ & [.143. .432] & $.16^{*}$ & {$[.024 ; .305]$} & $.28^{* *}$ & {$[.142 ; .418]$} & $.36^{* *}$ & {$[.23 . .477]$} \\
\hline H6b Interactions (friends and family) $\rightarrow$ Change & $.25^{* *}$ & {$[.118 ; .380]$} & $.27^{* *}$ & {$[.164 ; .385]$} & $.27^{* *}$ & {$[.150 ; .381]$} & $.28^{* *}$ & {$[.166 ; .403]$} \\
\hline H6c Interactions (friends and family) $\rightarrow$ Distract & $.42^{* *}$ & {$[.287 ; .537]$} & $.45^{* *}$ & {$[.339 ; .565]$} & $.53^{* *}$ & {$[.425 ; .621]$} & $.46^{* *}$ & {$[.339 ; .576]$} \\
\hline H7 Comply with basics $\rightarrow$ Coproduction & $.56^{* *}$ & {$[.414 ; .707]$} & $.39^{* *}$ & {$[.269 ; .508]$} & $.51^{* *}$ & {$[.374 ; .633]$} & $.39^{* *}$ & {$[.250 ; .547]$} \\
\hline H8 Colearn $\rightarrow$ Comply with basics & $.31^{* *}$ & {$[.154 ; .481]$} & $.24^{* *}$ & {$[.123 ; .349]$} & $.3^{* *}$ & {$[.193 ; .408]$} & $.37^{* *}$ & {$[.249 ; .481]$} \\
\hline H9a Collate $\rightarrow$ Diet and exercise & $.39^{* *}$ & {$[.259 ; .516]$} & $.24^{* *}$ & {$[.106 ; .366]$} & $.18^{*}$ & {$[.037 ; .318]$} & $.19^{* *}$ & {$[.060 ; .334]$} \\
\hline H9b Diet and exercise $\rightarrow$ Change & $.29^{* *}$ & {$[.167 ; .416$} & $.25^{* *}$ & {$[.149 ; .341]$} & $.21^{* *}$ & {$[.117 ; .312]$} & $.36^{* *}$ & {$[.242 ; .480]$} \\
\hline H9c Distract $\rightarrow$ Change & $.38^{* *}$ & {$[.244 ; .505]$} & $.42^{* *}$ & {$[.302 ; .530]$} & $.43^{* *}$ & {$[.311 ; .535]$} & $.27^{* *}$ & {$[.146 ; .397]$} \\
\hline H10a Coproduction $\rightarrow$ Well-being & $.23^{* *}$ & {$[.092 ; .375]$} & $.18^{*}$ & {$[.022 ; .329]$} & -.03 n.s. & {$[-.183 ;-.002]$} & -.08 n.s. & {$[-.225 ;-.006]$} \\
\hline H10b Diet and exercise $\rightarrow$ Well-being & $.43^{* *}$ & {$[.288 ; .567]$} & $.36 * *$ & {$[.193 ; .495]$} & $.44 * *$ & & .14 n.s. & {$[.012 ; .329]$} \\
\hline H10c Change $\rightarrow$ Well-being & $-.12 \mathrm{n} . \mathrm{s}$ & {$[-.291 ;-.008]$} & $-.26^{*}$ & {$[-.477 ;-.042]$} & $-.25^{* *}$ & {$[-.418 ;-.056]$} & $.36^{* *}$ & {$[.186 ; .545]$} \\
\hline
\end{tabular}

$* \mathrm{p}<.05, * * \mathrm{p}<.01$, n.s. $=$ non significant

Based on U.S. data) 
Appendix 1 Final measurement items

Interactions (1=strongly disagree, 7=strongly agree) Source: Developed from McColl-Kennedy et al. (2012) and current study with medical staff at the Interacted with medical staff at the medical center on a personal level medical center Put a great deal of effort into my relationship with the medical staff at the medical center

with friends and family

Shared my experience of this illness with my friends and family Put a lot of effort into nurturing a support network of friends and family

with other customers

Asked others with a similar experience to me for advice Gone out of my way to seek support from other patients Shared my experience to help others with the same illness

Activities (1=strongly disagree, 7=strongly agree) Source: Developed from McColl-Kennedy et al. ( 2012) and current study Coproduce Been involved with decisions about my treatment with the medical staff at the medical center

Made choices over medical decisions related to my treatment

Actively made suggestions on some aspects of the treatment process

Comply with basics

Done what the medical staff at the medical center tell me to do

Cooperated with medical staff

Strictly complied with my treatment regime

Colearn

Shared information about my condition with medical staff at the medical center Asked questions of the medical staff when discussing my condition Provided accurate feedback to the medical staff about what happened following the previous treatment

Collate

Done a considerable amount of research about my condition on my own Sought the latest research solutions offered by other medical practitioners Exhausted all available information sources

Diet and exercise

Change

Distract

Well-being

Physical well-being

Psychological well-being

Existential well-being

Support/social well-being
Monitored my diet

Maintained a healthy diet

Actively tried to eat foods that are good for me

Kept fit

Organized my day to day activities to fit around my health situation Changed the level of my activities so that I can manage my life better Changed things in my life to help my situation

Kept busy to distract myself from thinking about my situation Focused on my interests to stop thinking about my medical situation

Source: McGill’s MQOL (Cohen et al., 1996)

Physically I felt ( $0=$ terrible, $10=$ very well)

I was depressed ( $0=$ not at all, $10=$ extremely)

I was nervous $(0=$ not at all, $10=$ extremely)

I felt sad $(0=$ not at all, $10=$ extremely)

When I think about the future I am $(0=$ not afraid, $10=$ constantly terrified $)$

My personal existence is ( $0=$ utterly meaningless, $10=$ very purposeful and meaningful) In achieving life goals $(0=I$ have made no progress whatsoever, $10=I$ have progressed to complete fulfillment)

My life to this point has been ( $0=$ completely worthless, $10=$ very worthwhile)

I have $(0=$ no control over my life, $10=$ complete control over my life)

I feel good about myself as a person ( $0=$ completely disagree, $10=$ completely agree)

To me every day seems to be ( $0=\mathrm{a}$ burden, $10=\mathrm{a}$ gift $)$

The world is ( $0=$ an impersonal, unfeeling place, $10=$ caring and responsive to my needs)

I feel supported $(0=$ not at all, $10=$ completely $)$ 